\title{
Ninth Psychiatric Tutors' Conference
}

The Ninth Psychiatric Tutors' Conference was held in the pleasant surroundings of Ranmoor House, University of Sheffield, from 26 to 28 September, 1980. On this occasion, for the first time, the conference was organized jointly by the Psychiatric Tutors' Sub-Committee, the Collegiate Trainees Committee and APIT, and trainees were invited to attend the conference and to speak.

The first session was opened by DR Alyson Hall, who spoke on 'The Relationship between Tutor and Trainee'. Dr Hall presented the results of a questionnaire given to 67 trainees. The main problems in training were felt to be inadequate experience in the psychiatric sub-specialties and overwork. Forty-two per cent felt their consultant supervision was of good quality, but lack of consultant support at academic meetings was commented on. Only 38 per cent had any psychotherapy supervision. Trainees felt that regular appointments with their tutor, especially at the start of training, would have been useful. Eight per cent claimed not to know who their tutor was, and 56 per cent said they had no regular individual contact with him. More feedback was universally wanted and written assessments had been welcomed after initial anxieties.

Dr S. B. Mahapatra, discussing 'Assessment and Feedback', felt that many consultants preferred to avoid the trouble of assessing trainees and would rather leave this to the College and its examination results. However, he believed that the consultant must have the primary responsibility for assessing trainees. He emphasized the importance of in vivo assessments at the time and place of work, for which formal asesssments at the end of six-month attachments were not an adequate substitute. He also drew attention to the danger, in rotational training schemes, of consultants knowing too much about trainees before their attachment started. It emerged in discussion that a high proportion of tutors present used formal written assessments.

DR I. G. Bronks spoke on 'College Recognition of Tutors', and outlined the history and present position of the College Recognition Scheme. He mentioned proposals currently under consideration for placing the scheme on a permanent basis, and drew attention to the current debate about the extent to which the College should scrutinize tutors' credentials before granting recognition.

DR R. WILkINs, discussing 'The APIT Survey of Trainees', was critical of tutors, pointing out that over a third of trainees questioned had claimed not to have been taught how to carry out a mental state examination, and that over two thirds had said they had no supervision available in behaviour therapy. Library facilities were generally considered poor. He felt that trainees' progress should be more adequately monitored, again emphasizing the lack of personal contact with their tutors felt by many trainees, and acknowledged the value of truthful criticism.
In the afternoon of the first day the conference divided itself into two parallel sessions. Session A included contributions from DR E. B. GORDON on 'Books and Reading Lists', DR H. Ghadiali on 'The Problems of Overseas Trainees' and DR T. L. Pilkington on 'Audio-Visual Aids in the Teaching of Psychiatry'. Dr Gordon felt that there was little need for psychiatric textbooks in hospital libraries, monographs being much more useful. The services of a trained librarian were essential, preferably appointed by the Local Authority. Dr Ghadiali thought that little was done to help overseas doctors to assimilate British cultural values. Indian doctors tended to find the English aloof and distant; in India, consultants took a greater interest in the welfare of juniors. She suggested the appointment of regional advisors for overseas trainees. Dr Pilkington's historical survey of the development of audio-visual aids was followed by an impressive demonstration of equipment by Messrs. Saville.

Session B began with a discussion of psychiatric training for general practice. DR R. M. BERRINGTON favoured apprenticeship learning, using predominantly case discussion and random case analysis, supplemented by group learning experiences both in the practice and on half-day release. DR M. G. BARKER presented a psychiatrist's viewpoint. Professor G. W. Fenton discussed 'The Organization of Rotational Training Schemes in Psychiatry' with special reference to the Northern Ireland Programme. Registrar appointments are made in a block twice a year and include experience in general psychiatry and a variety of psychiatric specialties. There is a day release course for the MRCPsych. and one half-day per week for psychotherapy training. Finally DR R. Williams spoke under the provocative title 'The First Year of Training-Heaven or Hell?'.

A civic reception was followed by the Conference dinner in the magnificient surroundings of the Cutlers Hall. The Lord Mayor of Sheffield welcomed the conference, and Sir William Trethowan wittily compared the places of Sheffield and Birmingham in the development of psychiatric tutoring.

Professor A. C. P. Sims opened the final session by speaking on 'Teaching for the Preliminary Test'. He emphasized the importance of teaching in psychology; the Leeds Preliminary Test course comprised 96 hours, of which 26 were devoted to psychology. DR R. CostaIn described a survey carried out among trainees in the South West Division. Of 109 trainees questioned only 4 per cent thought the Preliminary Test should be abolished. Sixty-one per cent thought it should be more clinically relevant and 85 per cent wanted a more detailed syllabus.

DR A. M. P. Kellam opened his paper on 'The Teaching of Clinical Skills' by recalling that in 1959 the RMPA had recommended that teaching should take place in all psychiatric hospitals and that all consultants should teach. As well as the basic clinical skills-examination of the 
mental state, diagnosis and treatment procedures-he drew attention to the need for skill in teaching and administration, the latter especially important nowadays.

Psychotherapy training should be given on a longer parttime basis. He thought that systematic lectures were best replaced by a programme of reading supervised by seminar, but that there was a place for inspirational lectures by experts. He favoured examination candidates being allowed access to library and other facilities when answering essay questions. DR F. MARGISON, speaking as a trainee on the same topic, drew attention to the poor standard of skill in taking and recording case histories often shown by trainees. He felt that the use of headings improved the quality of recording in case notes, and suggested a short intensive course to teach interviewing skills. Feedback to trainees on their clinical work should be immediate. He demonstrated the use of video tapes in teaching clinical skills, but suggested that much cheaper audio cassettes were almost as effective.

The conference was generally felt to have led to a worthwhile exchange of views between tutors and trainees. Both talks and discussion were of an unusually high standard throughout, and those from the trainees were notably forthright and stimulating. Gratitude is owed to Dr T. Bewley, Dr C. P. Seager and Dr L. Tarlo, whose deft chairmanship of the various sessions oiled the conference wheels and miraculously kept it to time.

A final intriguing thought to emerge-should tutors be paid by their trainees?!

IAN G. BRONKS Secretary, Psychiatric Tutors' Sub-Committee.

\section{Examination Results}

\section{Preliminary Test-September 1980}

There were 336 candidates, of whom 195 passed.

Muwaffak Al-Mulla Khalaf Abdul-Hussain; Sourangshu Acharyya; Taiwo Abosede Adamson; Mutah Ismail Mohammed Alamin; Basil Mohammed Ali Alchalabi; John Thomas Alderdice; Saad Said Issa Al Khalaf; Mohammad A Hamid Salih Al-Samarrai; Harry Bertram Andrews; Indrani Anthony-Pillai; Richmond Nii Laryea ArmahKwantreng; Paul Robert Aylard;

Anthony William Baker; Tharumasothy Balarajan; Robert Charles Baldwin; Rosemary Anne Ball; Rina Banerjee; William Anthony Barker; Daphne Barnes; Marguerite Ann Barry; Magdi Zaki Barsoum; Charmaine Marie Bartlett; Judith Mary Beales; Michael Daniel Beary; Michael Beharry; Jacqueline Carol Benbow; Donald Francisco Bermingham; Bindumadhava Rao Bhadrinath; Charles Vernon Blacker; Nicola Susan Blandford; Ranjit James Winston Bolonna; Flora Botica; David Laurence Brash; Keith William Bridges; Julian Brian Paul Brockless; Andrew Playdon Templeton Brown; Sturla Erling BruunMeyer; James Graham Bryce; Gillian Mary Byers;

Richard Paul Caplan; Deborah Leigh Carter; Howard Robert Cattell; An Min Chai; Edwin Lewis Chaloner; Roberto Edward Chaskel; Evelyn Siang Lean Ng Cheongvee; Cheuk Ngen Chin; Alice Jane Mary Chisham; Kwong Tek Chong; Ronald Lun Piu Chu; Jonathan Charles Cohen; Helen Margaret Cooney; Francis Martin Corrigan; Michael Moore Corry; Marry Elizabeth Courtney;

Valerie Davidson; Susan Carol Davison; Vivien Deacon; Paul Andrew William Divall; Eileen Teresa Duffy;

Mohammed Saleem Flieh Elameer; Christian Lynton Sebaretnam Eliatamby; Abdelaziz Abdalla Elmahgoub; Magdy Youssef Kamal Abd. El-Wahab; Philip Charles Empson; Edmundo Raul Erba;
Basem Tawfik Farid; Don Bosco Fernandez; Michael Hugh Fielder; Wilson Rayner Firth; Paola Ginevra Franciosi; Emelia Fynn-Prah;

Jean Fenwick Garner; Timothy Patrick Noel Garvey; Rosemary Brenda Gaskin; Anindya Ghosh; Swapan Kumar Ghosh; Sheila Mary Gibson; Stephen William Green; Enyd Bevan Griffith; Eileen Patricia Groarke; Adrian Thomas Grounds; Elizabeth Anne Guinness; David Laurence Gunne;

Marguerite Elizabeth Handon; Richard Martin Hawley; Maureen Elizabeth Hillyear; Frank Holloway; Emad Salman Hussain;

Stephen Isaacs;

Ann Pauline Jackson; Hira Chand Jain; Joseph Pius Jegasothy; Jeffrey Royle Jones; Hoshang Nowshir Jungalwalla;

Madge Mary Kaczmarczuk; Selwyn Anthony Kaplan; Subbayah Kathirgamathamby; Norma Patricia Kearns; Basavanahall Seshadri Keshava; Ronald David Kimberley; David Graham Kingdon; Sugato Ranjan Konar; Sim Guan Kong; Sriya Ranjanee Kulupana; Vinod Kumar;

Timothy Christopher Lafferty; Maria Terezia Lakatos; Philip Meredith Lambert; Colin Paul Lanceley; Shung-Pun Leung; Winston Woon Chu Lim; Marilyn Loizou; Kieran Finbarr Lynch;

Charles Anthony McDowell; Patrick Kevin McGrath; Ramakrishna Madina; Tariq Mahmood; Mary Catherine Deirdre Mahood; Chinta Mani; Barbara Martin; John Christopher Martin; Roger Geoffrey Cadoux Martin; Barry James Matthews; Donald Ian Melville; Prem Kuman Menon; Yousuf Kamal Mirza; Diana Patricia Morrison; Paul Anthony Morrison; Evans Adam Pessa Muluka; James 